\title{
movimento
}

faculdade de educação - programa de pós-graduação em educação

universidade federal fluminense issn 2359-3296

ano 3 número 5 - 2016

\section{A EDUCAÇÃO ESCOLAR E A REDE PRIVADA: Concessão e Autorização}

Carlos Roberto Jamil Cury ${ }^{1}$

\section{RESUMO}

Este artigo pretende explorar a presença do setor privado na oferta da educação escolar no Brasil. Por meio de uma evolução histórico-cronológica baseada na legislação nacional referida na história da educação brasileira, pode-se apreender diferentes conceitos como o de concessão e o de autorização. E sob tais conceitos a iniciativa privada na educação escolar também se dividiu entre instituições com fins lucrativos e instituições sem fins lucrativos. De qualquer modo, salvo raras exceções, os conceitos de concessão e de autorização significam que tais instituições dependem do poder do Estado para os certificados e diplomas por elas emitidos tenham valor oficial.

Palavras-chave: Educação Escolar Privada; Educação Privada e Concessão; Educação Privada e Autorização de funcionamento.

\section{RESUME}

This article intends to examine the presence of the private sector in the institutions of education in Brazil. Through an evolution based as much as in the historical evolution and in the national legislation of brazilian education, it is possible to apprehend diferent conceptions as concession and authorization. And under such conceptions the free enterprise in the education also is divided between free enterprises with profit-making purpose and free enterprises with non-profit purpose. In such a way, except scarce situations, the concepts of concession and authorization mean that such institutions depend of the State's power to obtain official value to the certificates and the degrees issued.

Key-words: Private education; Private Education and Concession; Private Education and operating authorization.

\footnotetext{
${ }^{1}$ Doutor, PUC Minas. E-mail: crjcury.bh@terra.com.br
} 


\section{movimento \\ faculdade de educação - programa de pós-graduação em educação \\ universidade federal fluminense issn 2359-3296 \\ ano 3 número 5 - 2016}

\section{Introdução}

Este ensaio pretende captar um ângulo, no meio de tantos, da relação público versus privado, na organização nacional da educação escolar brasileira.

O ângulo específico a ser enfocado é o da noção de concessão e de autorização pelo Estado de um serviço público - no caso a educação escolar regular - a qualquer pretendente provindo da iniciativa particular. A concessão vigeu desde as reformas imperiais até a Constituição de 1988. Já a partir desta, a relação educação escolar e rede privada passou a viger à luz do conceito de autorização.

Há um conhecimento bastante disseminado sobre a relação educação escolar que ela é dever do Estado e direito do cidadão e, assim, ela é adequadamente assumida como função pública e, de modo geral, como um bem público.

O que se pretende é ver, de modo específico, no histórico da questão, alguns elementos legais que nos permitam matizar um pouco mais esta função pública quando autorizada para o ente privado.

Este estudo se baseia, fundamentalmente, na legislação concernente ao assunto. Para tanto, toda a legislação citada até a Constituição de 1988 tem como fonte o Portal da Câmara do Deputados, http//:www2.camara.legbr/atividade - legislativa/legislacao. Para as leis do Império, foi acessado, dentro do Portal, o link Coleção das Leis do Império (18081889) e para o acesso às leis da República, o link Coleção de Leis da República (1889-2000). Para a legislação entre a Constituição de 1988 e os dias atuais, foi 


\section{movimento}

faculdade de educação - programa de pós-graduação em educação

universidade federal fluminense issn 2359-3296

ano 3 número 5 - 2016

acessado 0 Portal da Presidência da República www2.planalto.gov.br/acervo/legislacao. Há um link específico para a Constituição de 1988. Para um melhor entendimento da identificação de um diploma legal, no período entre 1808 e os dias atuais, pode-se consultar Martins Filho (1999).

A importância dessa questão é reforçada por significativas mudanças constitucionais. A Constituição Federal de 1988 estabeleceu, em seu art. 206, que o ensino será ministrado com base nos seguintes princípios... e seguem 8 incisos e um parágrafo único. O inciso III dispõe que um dos princípios é a coexistência de instituições públicas e privadas. Entretanto esta coexistência, no caso das instituições privadas, tem o art. 209 voltado para o ensino oferecido por estas instituições. Ei-lo: (Brasil, 1988)

O ensino é livre à iniciativa privada, atendidas as seguintes condições:

I - cumprimento das normas gerais da educação nacional;

II - autorização e avaliação de qualidade pelo poder público

A coexistência, ou seja, a existência simultânea entre o público e privado, se voltado para o ensino da educação escolar, depende das condições postas no artigo 209. Trata-se, pois, do reconhecimento destas instituições, coexistentes com as públicas, porém dentro de condições postas na legislação e não um laissez-faire.

Posta esta premissa básica, a Constituição passa a categorizar, não só no capítulo da educação, mas também em outros artigos, a pluralidade institucional de oferta da educação escolar. 


\section{movimento \\ faculdade de educação - programa de pós-graduação em educação \\ universidade federal fluminense issn 2359-3296 \\ ano 3 número 5 - 2016}

\section{Escola Livre e Escola Regular}

A Constituição atual, dentro de um sentido mais amplo, explicita um gênero de escola e ao fazê-lo deixa um outro implícito. Trata-se da distinção básica entre escolas regulares e escolas livres.

De pronto, esclareça-se a escola livre: ela é mantida por pessoas jurídicas ou físicas, fora do sistema de controle educacional oficial. Exemplo constante de escola livre é aquele que oferece ensino de idiomas estrangeiros ou os chamados cursinhos para processos seletivos de qualquer natureza. Deles não se exigem, por exemplo, currículos mínimos oficiais e nem eles se submetem às autoridades de ensino em termos de autorização de funcionamento. Em contrapartida, não sendo autorizadas por estas autoridades, não podem expedir diplomas oficiais. Livre a escola, livre é a aceitação do valor de seu diploma que pode ter valor de mercado. Ela, como qualquer outro estabelecimento de serviços, está sujeita apenas às normas gerais da legislação brasileira como alvarás municipais, respeito a códigos de posturas, entre outros.

As regulares são as que, além de se submeterem às leis gerais do país, também se submetem ao sistema de diretrizes e bases da educação nacional, inclusive para o reconhecimento formal de seus atos e diplomas. Regular provém do latim regula, regulae e indica a lei, a regra. Por isso escola regular é a que está sub lege. 


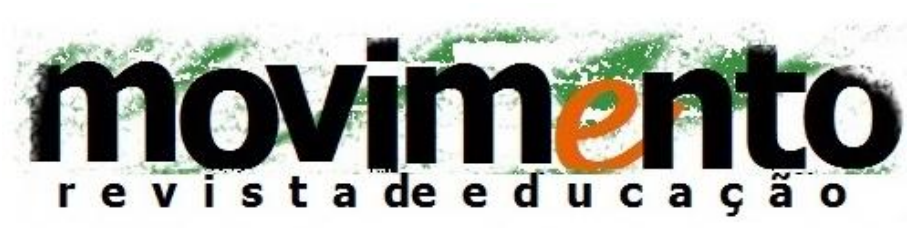

faculdade de educação - programa de pós-graduação em educação

universidade federal fluminense issn 2359-3296

ano 3 número 5 - 2016

Por sua vez, a escola regular, como gênero, se subdivide em duas espécies: as públicas e as privadas. As primeiras são oficiais por sua natureza jurídica já que advém do próprio Estado. Além da educação escolar regular ser dever (officium em latim, donde oficial) do Estado (art. 205 da Constituição Federal), ela promana da autoridade do mesmo e possui larga história em nosso ordenamento jurídico. As segundas tornam-se oficializadas na medida em que se submetem aos parâmetros legais necessários para a consecução de uma validade oficial de sua presença nesta oferta e de seus certificados e diplomas. Embora tais escolas não se transformem em oficiais, a elas são atribuídas as mesmas características das oficiais no que se refere ao ensino e aos certificados e diplomas, obedecidas as diretrizes e bases educação.

As escolas públicas, por seu lado, se distinguem em: federais, distrital, estaduais e municipais. Ou seja, elas se distribuem segundo sua pertença respectiva aos entes federativos e, consoante suas competências legais, abrangendo os mais diversos níveis e as mais diferentes etapas da educação.

As escolas privadas, por meio de uma dedução lógica (conquanto implícita) do texto constitucional de 1988, se diferenciam, por sua vez, em lucrativas e nãolucrativas. Como o texto constitucional não explicita diretamente tal diferença, é preciso deixar claro o que se deve entender por escola lucrativa e o que se deve entender por não-lucrativa.

E esta diferenciação representa uma ruptura? Qual e em que sentido?

A ruptura se dá com a inclusão, no texto constitucional, da categoria escola privada lucrativa, algo até então juridicamente inexistente no sistema regular de ensino. E era juridicamente inexistente porque, pelo menos desde os anos 30, 0 


\section{movimento \\ faculdade de educação - programa de pós-graduação em educação \\ universidade federal fluminense issn 2359-3296 \\ ano 3 número 5 - 2016}

Estado reservava a si a competência para conceder a pleiteantes privados a função pública inerente à escola pública sem se referir à lucratividade ou mesmo proibindo-a, a depender da reforma de educação. Isto não quer dizer que tais escolas deviam ser gratuitas. Apenas ou não havia referência à lucratividade ou esta era interdita, assinalando tratar-se a educação de um bem público.

Logo, havia apenas dois gêneros de escolas: as públicas e as privadas, sendo que estas últimas, pertencentes aos sistemas públicos de educação, eram consideradas privadas com função pública concedida pelo Estado. Toda e qualquer escola deveria visar o interesse coletivo antes de tudo. Contudo, no estudo das reformas educacionais, percebe-se que, no interior de tais gêneros, fazia-se distinção entre aquelas que praticavam algum tipo de gratuidade e com isto faziam jus a recursos emanados dos poderes públicos e as que simplesmente exerciam tal função como iniciativa privada típica do sistema contratual de mercado. 


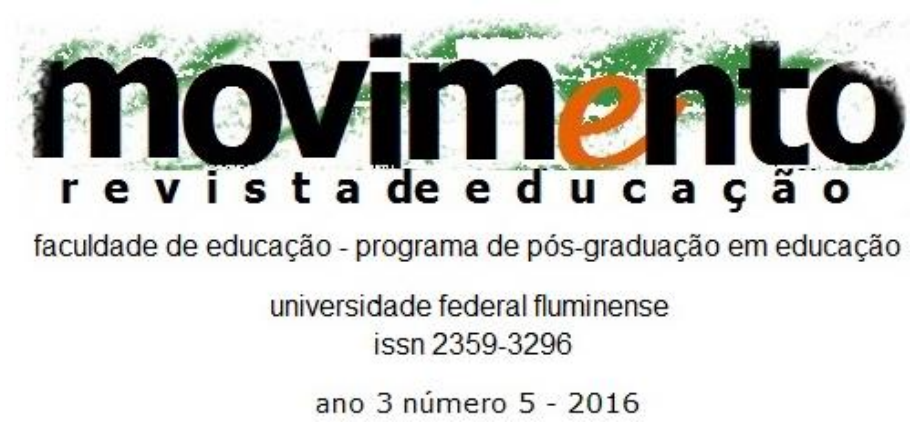

\section{Esboço evolutivo da Relação Público x Privado.}

Para se entender melhor esta questão, será necessário recorrer à evolução dos deslocamentos que se processaram na História da Educação, em que se cruzam o público e o público atribuído ao privado.

A distinção entre a escola regular, ou seja, oficial ou oficializada, mantida ou concedida pelo Estado sempre fez parte de nossas leis educacionais.

No Império, o Decreto n. 1.331-A de 17 de fevereiro de 1854, também chamado de Reforma Couto Ferraz, dispunha no $\S 30$ do art. 3o que a inspeção dos estabelecimentos públicos e particulares seria exercida pelo inspetor geral de modo a: "Autorizar a abertura de escolas e estabelecimentos particulares de instrução, guardadas as disposições deste Regulamento." Brasil, 2016a)

Tais disposições ganharam todo um Título, o IV em Capítulo Único com 16 artigos, pelos quais se regulavam a autorização e a inspeção do ensino particular e primário entre as quais a moralidade e capacidade profissional dos docentes.

Este Decreto, no caso da oferta particular de ensino, tem grande importância já que ele recolocava o papel do Estado na regulamentação do ensino privado. Como se sabe, D. João VI, um pouco antes de sua partida para Portugal, em 30 de junho de 1821, por meio de um decreto assinado em 28 de junho, permitiu a qualquer cidadão a abertura de escolas livres de exame ou de alguma licença para a oferta de primeiras letras. 


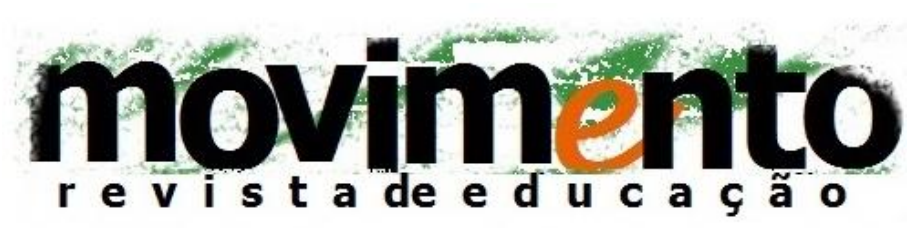

faculdade de educação - programa de pós-graduação em educação

universidade federal fluminense issn 2359-3296

ano 3 número 5 - 2016

O Decreto №. 7.247 de 19/4/1879, da denominada Reforma Leôncio de Carvalho, dizia, em seu art. 1, que: "É completamente livre o ensino primário e o secundário no município da corte e o superior em todo o Império, salvo a inspeção necessária para garantir as condições de moralidade e higiene." (Brasil, 2016a)

E seguem as exigências relativas a condições de funcionamento e a obrigações de informes que, se não atendidas, poderiam gerar multas ou mesmo interdição de oferta de ensino.

O art. 8 permitia subvenção às escolas particulares, desde que não havendo escola públicas por perto: "[...] inspirem a necessária confiança e mediante condições razoáveis se prestem a receber e ensinar gratuitamente os meninos pobres da freguezia." (Brasil, 2016a)

Desde logo se percebe que das escolas livres se exige "moralidade e higiene" (a República acrescentará a exigência da estatística). Mas, quando estas compensam o déficit do Estado na oferta de vagas destinadas a "meninos pobres", elas podem receber recursos públicos, desde que haja gratuidade e "condições razoáveis" de funcionamento. Esta razoabilidade pode ter como um de seus indicadores uma certa contenção do anseio lucrativo.

Por seu lado, pelo mesmo Decreto, art. 8, inciso VI, o uso do nome escola normal livre, para formação de docentes, pelo qual esta se equipararia, em termos de prerrogativas, às escolas oficiais, era, explicitamente, uma concessão do Estado. 


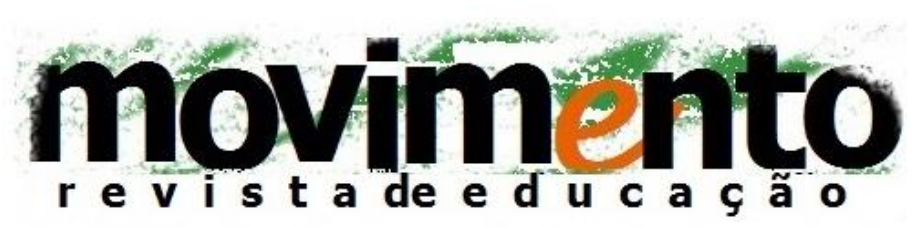

faculdade de educação - programa de pós-graduação em educação

universidade federal fluminense issn 2359-3296

ano 3 número 5 - 2016

O mesmo se aplicava aos cursos de ensino superior os quais, de acordo com o art. 21 do Decreto, seriam permitidos, mas o uso do nome "faculdade livre" seria uma concessão do poder legislativo.

O decreto teria ficado, segundo Rui Barbosa (1947), no mofo e traçaria dos arquivos. Isto não significa que a Reforma Leôncio de Carvalho não haja se constituído em parâmetro para as reformas educacionais das Províncias e mesmo para as posteriores da República.

O importante é notar, desde logo, o entrecruzamento ou sobreposição entre a escola livre (privada), autorizada por concessão e a escola compensatória do dever.

Com a Proclamação da República, a situação continuou, quanto a este aspecto, mais ou menos a mesma, exceto o princípio da laicidade nos estabelecimentos oficiais, consequente à separação entre Igreja e Estado em 1890. Apesar dos esforços dos positivistas em não acatar a distinção entre escola oficial e escola livre, tal dispositivo permaneceu na Constituição e nos Códigos posteriores, com exceção da Reforma Rivadávia.

O Decreto №. 981 de 8/11/1890, de Benjamin Constant, regulamentou o ensino primário e secundário do Distrito Federal. Em seu art. 1 ele determinava: "É completamente livre aos particulares, no Distrito Federal, o ensino primário e o secundário, sob condições de moralidade, higiene e estatística definidas nesta lei."

Mas, para se tornar oficializado o ensino ministrado nos estabelecimentos privados, o estudante pretendente à oficialização de seus estudos deveria 


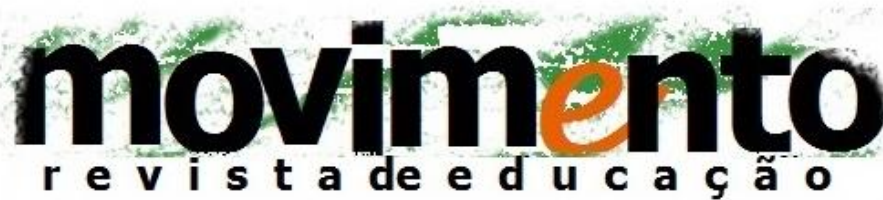

faculdade de educação - programa de pós-graduação em educação

universidade federal fluminense issn 2359-3296

ano 3 número 5 - 2016

prestar os exames de madureza do Ginásio Nacional (ex-Colégio de Pedro II) de acordo com os art. 39 e 40.

Permanece, então, a faculdade de abertura de estabelecimentos particulares (segundo o art. 53, III) cuja autorização de abertura ficava condicionada ao placet das autoridades oficiais como forma de reconhecimento da parte do Estado.

Por seu turno, dizia o art. 71:

Nas localidades em que ainda faltarem escolas públicas do $1 \%$ grau, ou em que elas não bastem à grande população escolar, poderão ser subvencionadas as escolas particulares, que receberem e derem instrução gratuitamente a 15 alunos pobres, pelo menos; esta subvenção será então de $60 \$$ mensais, e por aluno, que acrescer aos 15 , se adicionará a quota de $4 \$$ até perfazer a subvenção de $120 \$$ que se não poderá exceder. (Brasil, 2016b)

Percebe-se, pois, a existência de várias modalidades de escola: a escola livre (privada), a escola livre (privada) subvencionada e a escola oficial (sendo esta última o critério para a oficialização de diplomas expedidos por escolas livres).

O Decreto n. 3.890 de 1ํ de Janeiro de 1901 estabelece um outro Código dos Institutos Oficiais do Ensino Superior e Secundário. Com 384 artigos e mais 3 nas disposições provisórias, o título II do mesmo código regulamenta a criação de estabelecimentos de ensino superior e secundário nos Estados ou por particulares. É assinado pelo Presidente Campos Salles e por Epitácio Pessoa, Ministro da Justiça e Negócios Interiores. Diz o art. 361: "Aos estabelecimentos de ensino superior ou secundário fundado pelos Estados, pelo Districto Federal ou por qualquer associação ou indivíduo, poderá o Governo conceder os privilégios dos estabelecimentos federaes congêneres." (Brasil, 2016b) 


\section{movimento \\ faculdade de educação - programa de pós-graduação em educação \\ universidade federal fluminense issn 2359-3296 \\ ano 3 número 5 - 2016}

Esse conceder, que implicava o reconhecimento, a equiparação e o gozo de tais privilégios, importava em múltiplas e minuciosas condições como a aquisição de individualidade própria como sociedade civil, um conjunto de informações documentadas e a submissão à inspeção permanente. Quando não alinhadas às condições, as prerrogativas eram suspensas ou cassadas. Explicita-se mais: quem tem o poder de conceder, tem o de suspender ou cassar.

A ânsia pela liberdade de ensino, defendida por vários próceres leigos e religiosos, a penetração do ideário positivista no governo central são alguns dos condicionantes pelos quais o Mal. Hermes da Fonseca, presidente da República e o Ministro Rivadávia Correia assinam o decreto n. 8659 de 5 de abril de 1911. Inspirado na doutrina positivista, a Lei Orgânica do Ensino Superior e do Fundamental na República, com 140 artigos, será o primeiro documento onde a desoficialização do ensino federal é explicitamente assumida.

A expressão do art. 10. é emblemática: "A instrucção superior e fundamental, diffundidas pelos institutos creados pela União, não gosarão de privilégio de qualquer especie." (Brasil, 2016b)

A figura jurídica dos institutos oficiais muda-se, de acordo com o art. 20. "Os institutos, até agora subordinados ao Ministério do Interior, serão, de ora em diante, considerados corporações autônomas, tanto do ponto de vista didactico, como do administrativo." (Brasil, 2016b)

O art. 3o. já tendo os estabelecimentos federais como corporações Ihes faculta personalidade jurídica "para receberem doações, legados e outros bens e 


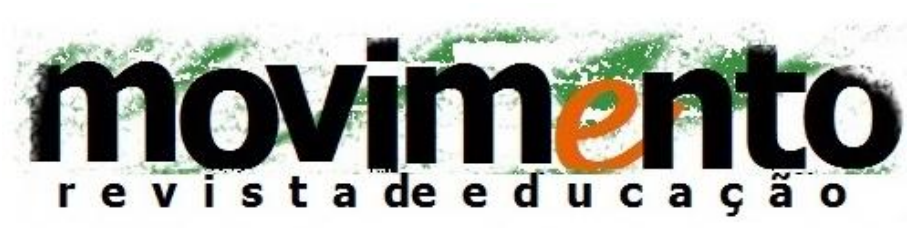

faculdade de educação - programa de pós-graduação em educação

universidade federal fluminense issn 2359-3296

ano 3 número 5 - 2016

administrarem seus patrimônios, não podendo, contudo, sem autorização do Governo, aliená-los." (Brasil, 2016b)

A Lei Orgânica, pelo art. 5o., cria o Conselho Superior do Ensino. Sua principal atribuição será a de substituir a funcção fiscal do Estado. De acordo com o mesmo artigo, o Conselho Superior de Ensino: “ [...] estabelecerá as ligações necessárias e imprescindíveis no regime de transição, que vae da officialização completa do ensino ora vigente, à total independência futura, entre a União e os estabelecimentos de ensino." (Brasil, 2016b)

Deliberativo e consultivo, este Conselho fiscalizaria os institutos de modo a, progressivamente, ir repassando a função fiscal aos próprios estabelecimentos, conforme os artigos 138 e 139.

Assim, pelo art. 6o. e art. 40, os institutos como corporações são dotados de autonomia didática completa e, pelo art. $7^{\circ}$, cabe-Ihes a autonomia gerencial de seus patrimônios. Os recursos de manutenção dos institutos, além de legados, doações, ensino pago, contariam também "com as subvenções votadas pelo Congresso federal".

A Lei cria, pelo art. 65, o exame de admissão ao ensino superior. Mais tarde, outros decretos denominarão de vestibular este exame. Contudo, as matérias dos institutos deveriam não só ser seriadas (art. 74), quanto em seu conteúdo serem estabelecidas pelo "nexo scientífico que as ligarem, indo do mais simples ao mais complexo" (Brasil, 2016b), de acordo com o método positivista de aproximação da ciência. 


\section{movimento \\ faculdade de educação - programa de pós-graduação em educação \\ universidade federal fluminense issn 2359-3296 \\ ano 3 número 5 - 2016}

A desoficialização federal propiciada pela Reforma Rivadávia oportunizou a abertura de escolas de todos os tipos. Surgiram algumas escolas sérias e, sob o impacto de um mercado aberto, surgiram também as famosas "academias elétricas" de qualidade mais que duvidosa. Ora, esta face mercantilista de uma lucratividade sem peias conduz os novos governantes que assumiram o governo federal em 15 novembro de 1914 à reinstauração do ensino oficial, com o retorno do instituto da equiparação.

Com 201 artigos, dos quais 144 no corpo permanente, o decreto n. 11.530 de 18 de março de 1915, assinado pelo presidente Wenceslau Braz e por Carlos Maximiliano, ministro da Justiça e Negócios Interiores, reorganiza o ensino secundário e o superior na República e, com isto, reoficializa o ensino.

A iniciativa privada não perde a liberdade de atuação junto ao ensino, mas agora ela é denominada de academia e volta a ser regrada pelo instituto da equiparação, sendo controlada e fiscalizada pelo Conselho Superior do Ensino, conforme 0 art. 28.

Diz o art. 11: "As academias que pretenderem que os diplomas por ellas conferidos sejam registados nas repartições federaes, afim de produzirem os fins previstos em leis vigentes, requererão [...]."(Brasil, 2016b)

Retornam os controles minuciosos para autorização de funcionamento, equiparação, possibilidade de cassação (art. 14-20) e "na falta de qualquer dos requisitos enumerados no artigo antecedente, o inspetor concluirá por aconselhar que não se conceda a pretendida equiparação [...]”. (art. 14). (Brasil, 2016b) 


\section{movimento \\ faculdade de educação - programa de pós-graduação em educação \\ universidade federal fluminense issn 2359-3296 \\ ano 3 número 5 - 2016}

Tanto é assim que o art. 20 diz: "julgada digna de equiparação às federaes uma academia, será essa regalia outorgada pelo Ministro [...]." (Brasil, 2016b)

O art. 24 proíbe a equiparação ao Pedro II de qualquer instituto público estadual ou particular de ensino secundário que se estabeleça com intento de lucro ou de propaganda filosófica ou religiosa.

Já o art. 25 proíbe a equiparação de qualquer academia em cidades com menos de 100.000 habitantes, salvo se capital de Estado o qual, por sua vez, possua mais de 1 milhão de habitantes e seja tal instituto "fortemente subvencionado pelo governo regional". (Brasil, 2016b)

A reforma João Alves, Ministro da Justiça e Negócios Interiores, mais conhecida como Rocha Vaz, assinada pelo presidente Artur Bernardes, data de 13 de janeiro de 1925, é referida pelo decreto n. 16.782. Com 310 artigos, o decreto cria o Departamento Nacional de Ensino, embrião do futuro Ministério da Educação, revoga o Conselho Superior de Ensino e institui o Conselho Nacional de Ensino. Dele poderiam fazer parte também os representantes dos estabelecimentos equiparados escolhidos pelos seus representados.

Pelo art. 22, cabia a este Conselho, entre outras atribuições o de "dar parecer sobre a equiparação de institutos de ensino particulares ou dos Estados aos oficiais [...] propor a cassação ou suspensão das regalias da equiparação." (Brasil, 2016b)

Com a Revolução de 30, o Governo Provisório de Vargas (1930-1934) tomou uma série de medidas no campo educacional: autorizou o ensino religioso em 


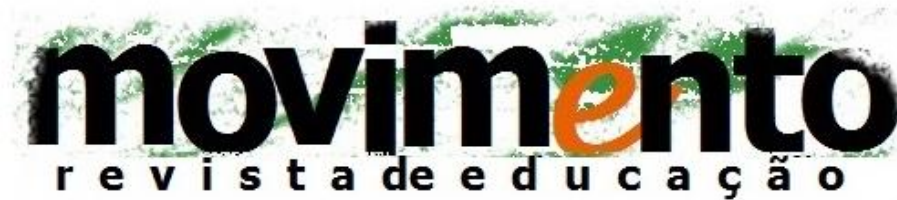

faculdade de educação - programa de pós-graduação em educação

universidade federal fluminense issn 2359-3296

ano 3 número 5 - 2016

escolas oficiais, reorganizou o ensino secundário, oficializou os currículos em escolas regulares e criou o Conselho Nacional de Educação.

A discussão, no interior da classificação das escolas, não será mais sobre escola livre ou academia versus escola oficial. Agora, com a oficialização dos currículos, o deslocamento será sobre ensino público versus ensino privado.

No âmbito da reorganização do ensino, o Decreto №. 19.890, de 18/4/1931, em seu art. 1 dizia: "O ensino secundário, oficialmente reconhecido, será ministrado no Colégio Pedro II e em estabelecimentos sob regime de inspeção oficial." (grifo nosso) (Brasil, 2016b)

Logo, o Colégio Pedro II continuava a ser o paradigma do ensino público como ensino oficial e dele promanavam os critérios para estabelecimentos privados que quisessem a oficialização, previamente submetidos à inspeção estatal.

E o que é esta oficialização?

O art. 44, sob o título II (Inspeção do Ensino Secundário) diz:

Serão oficialmente equiparados para 0 efeito de expedir certificados de habilitação, válidos para os fins legais, aos alunos nele regulamente matriculados, os estabelecimentos de ensino secundário mantidos por governo estadual, municipalidade, associação ou particulares, observadas as condições abaixo prescritas. (Brasil, 2016b) 


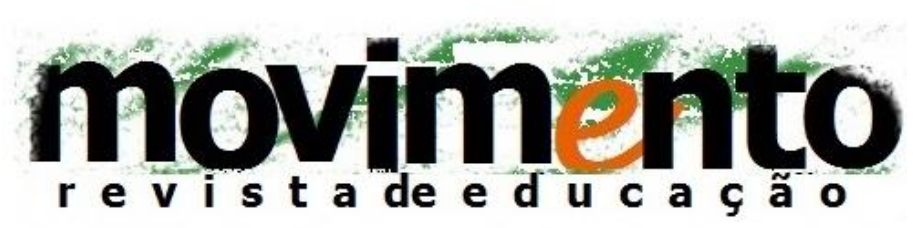

faculdade de educação - programa de pós-graduação em educação

universidade federal fluminense issn 2359-3296

ano 3 número 5 - 2016

Lê-se, em seguida, no art. 48: "A concessão da equiparação ou inspeção permanente se fará por decreto do Governo Federal mediante proposta do Conselho Nacional de Educação [...]"

Também o art. 45 diz: "A concessão, de que trata o artigo anterior, será requerida ao Ministro da Educação e Saúde Pública, que fará verificar pelo Departamento Nacional de Ensino se o estabelecimento satisfaz as condições essenciais de [...]."(Brasil, 2016b)

Logo, a equiparação do estabelecimento ao Colégio Pedro II não é um direito, mas é uma concessão que o poder público a si avoca e que impõe a este estabelecimento uma função social que nele não preexistia.

Já o Decreto no. 19.851, de 11/4/1931, diz, no art. 12, que as universidades livres poderão ser equiparadas às universidades federais mediante inspeção prévia e outros critérios.

E o Decreto №. 21.241, de 4/4/1932 (Consolidação da Organização do Ensino Secundário) repõe no art. 50 as mesmas exigências do decreto de 1931.

O Decreto n‥ 19.890, art. 49, fala inclusive, em suspensão da concessão caso a inspeção oficial constatasse irregularidades ou desvios.

Esta imputação da função pública como concessão do Estado também permaneceu sob o Estado Novo (1937-1945), apesar do caráter privatista do texto constitucional outorgado em 1937. 


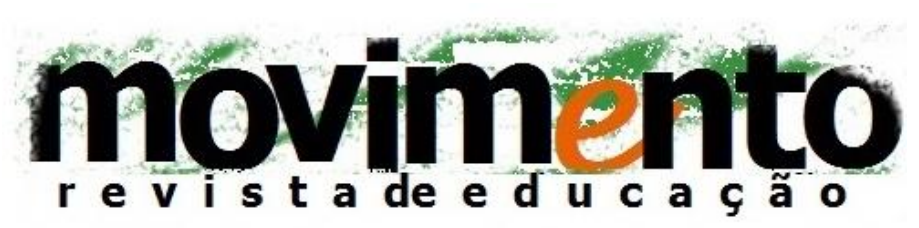

faculdade de educação - programa de pós-graduação em educação

universidade federal fluminense issn 2359-3296

ano 3 número 5 - 2016

O Decreto-Lei no. 4.244, de 19/4/1942, conhecido como Lei Orgânica do Ensino Secundário, diz, no capítulo sobre a organização escolar, respectivamente nos art. 69 e 70 :

O ensino secundário será ministrado pelos poderes públicos e é livre à iniciativa particular.

As pessoas naturais e as pessoas jurídicas de direito privado, que mantenham estabelecimentos de ensino secundário, são consideradas como no desempenho de função de caráter público. Cabem-lhes, em matéria educativa, os deveres e as responsabilidades inerentes ao serviço público. (Brasil, 2016b)

A parte final do art. 70 dispensa comentários pela sua clareza. Mas o DecretoLei estabelece uma outra categorização do ensino. Além do ensino oficial (cujo paradigma é o Pedro II) ele distingue os estabelecimentos equiparados (a rede pública estadual e do Distrito Federal) e os reconhecidos (geridos pelos municípios e por pessoas e direito privado que tenham solicitado e obtido a autorização do governo federal).

Torna-se evidente não só a liberdade de ensino como prerrogativa da iniciativa privada, como também que o gozo da equiparação ou do reconhecimento são uma concessão do Estado. Neste último caso, o ímpeto possessivo do lucro permitido em escolas livres deve ceder o passo à função pública atribuída.

E como será que se posicionaram as diferentes leis de diretrizes e bases da educação nacional a este respeito?

Com a redemocratização em 1946, o governo Dutra, em obediência ao mandato constitucional, por meio de seu ministro da educação, Clemente Mariani, envia 


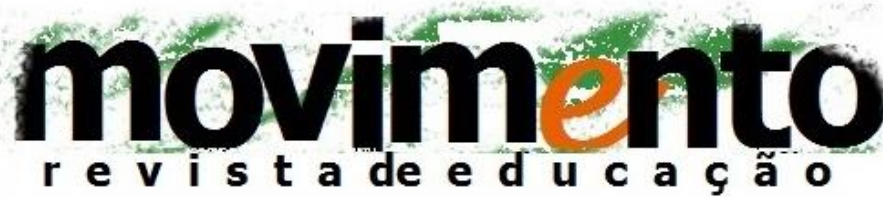

faculdade de educação - programa de pós-graduação em educação

universidade federal fluminense issn 2359-3296

ano 3 número 5 - 2016

o projeto original de diretrizes e bases, datado de 28/10/1948, cujo art. 11, parágrafo 2, diz:

Os serviços educacionais dos Estados e do Distrito Federal promoverão a classificação das escolas particulares incorporadas ao seu sistema, sobre a base de satisfação dos requisitos exigidos para seu funcionamento, fazendo-a publicar para conhecimento dos pais e responsáveis. (Brasil, 2016b)

É significativo o uso da expressão incorporadas. É como se algo vindo de fora (escola particular) e, mediante a satisfação de requisitos prévios, passe, então, a fazer parte de uma rede orgânica mediatizada pelo Estado.

O art. 12 impõe as condições mínimas para esta incorporação e reconhecimento.

Por seu turno, as Diretrizes e Bases da Educação Nacional, Lei nํ. 4.024/62, ao reconhecer a liberdade de ensino, diz no art. 5: "São assegurados aos estabelecimentos de ensino públicos e particulares e legalmente autorizados, adequada representação nos conselhos estaduais de educação, e reconhecimento, para todos os fins, dos estudos neles realizados.

E a ideia de reconhecimento adentra o capítulo dos sistemas de ensino, em cujo art. 19 se lê: "Não haverá distinção de direitos, entre os estudos realizados em estabelecimentos oficiais e os realizados em estabelecimentos particulares reconhecidos." (Brasil, 2016b)

Por sua vez, a Lei nํ. 4.024/61 com a redação dada pela Lei no. 5.692/71 não revogou estes artigos da Lei. Pelo princípio da recepção até mesmo os incorporou. Tanto é que o art. 45 diz que a iniciativa privada poderá receber 


\section{$\operatorname{movim}_{\text {revistade educąis }}$}

faculdade de educação - programa de pós-graduação em educação

universidade federal fluminense issn 2359-3296

ano 3 número 5 - 2016

recursos técnico-financeiros do poder público "quando suas condições de funcionamento forem julgadas satisfatórias pelos órgãos de fiscalização [...]."(Brasil, 2016b)

Também pelo art. 16 da mesma Lei ㄲo. 5.692/71, no seu parágrafo único, os diplomas de habilitação profissional, para que tenham "validade nacional... deverão ser registrados em órgão local do Ministério da Educação." (Brasil, 2016b)

Enfim, o art. 2 da Lei №. 5.692/71 fala em critérios para a criação de escolas, além do núcleo comum fixado para todo o território nacional.

Vê-se, pois, que a Educação, enquanto lugar de transmissão de conhecimentos, de socialização, de preparação para o exercício de atividades profissionais e de democratização política, é vista como uma função pública inerente ao Estado. E como tal goza de reconhecimento implícito na destinação universal e na capacidade de controle e monitoramento.

O sujeito privado, detentor do ímpeto possessivo, tanto pode ficar adstrito ao mercado (neste caso usufrui do lucro e em contrapartida não goza do reconhecimento oficial), quanto pode querer o usufruto da equiparação ou do reconhecimento. Neste último caso, ele cai na figura jurídica chamada concessão.

[...] concessão [...] é a transferência, a outorga a terceiros dos poderes, ou de alguns poderes, vantagens, utilidades que pertencem ao concedente e que, por efeito da própria concessão, passam ao concessionário, reservando-se, entretanto, o concedente alguns dos direitos, vantagens ou utilidades. (Naufel, 1988, p. 306). 


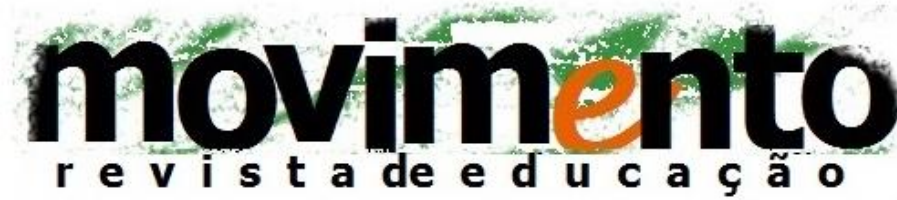

faculdade de educação - programa de pós-graduação em educação

universidade federal fluminense issn 2359-3296

ano 3 número 5 - 2016

Esta transferência é privativa do concedente, dentro de determinadas condições. No caso de concessão de serviço público, inclui sempre a concepção de interesse coletivo ou de bem comum do qual o concedente continua titular.

\section{A Constituição de 1988 e a Ruptura da Posição Histórica}

A redação da nova Constituição dá continuidade a esta dimensão própria do Estado no campo do ensino como agente concedente de autorização, de avaliação e detentor do monopólio da atribuição dos graus de ensino. O art. 209 dispõe:

O ensino é livre à iniciativa privada, atendidas as seguintes condições:

I - cumprimento das normas gerais da educação nacional;

II - autorização e avaliação de qualidade do poder público. (Brasil, 1988)

E qual seria a diferença entre concessão e autorização?

De acordo com Meirelles (1993, p.353):

Serviços autorizados são aqueles que o Poder Público, por ato unilateral, precário e discricionário, consente na sua execução por particular para atender a interesses coletivos instáveis ou emergência transitória. [...] Seus executores não são agentes públicos, nem praticam atos administrativos; prestam, apenas, um serviço de interesse da comunidade, por isso mesmo controlado pela Administração e sujeito à sua autorização. (grifos do autor) 


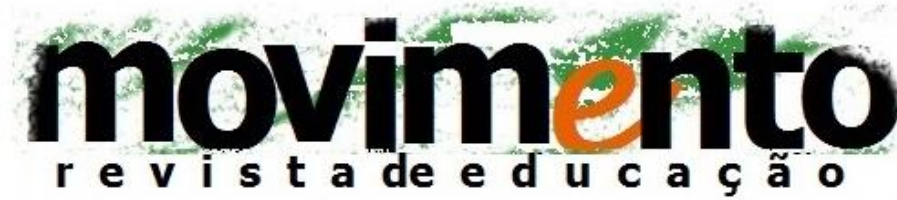

faculdade de educação - programa de pós-graduação em educação

universidade federal fluminense issn 2359-3296

ano 3 número 5 - 2016

Ou na conceituação de Di Pietro (2004, p.219):

Pode-se, portanto, definir a autorização administrativa, em sentido amplo, como ato administrativo unilateral, discricionário e precário pelo qual a Administração faculta ao particular o uso privativo de bem público, ou desempenho de atividade material, ou prática de ato que, sem esse consentimento, seriam legalmente proibidos. (grifos do autor)

Entretanto vale a observação de Bandeira de Mello (2006, p.409):

Cumpre observar que a terminologia com que os atos administrativos são rotulados é muito incerta, inexistindo concordância total entre os autores com respeito à identificação exata tal qual debaixo de uma designação uniforme. $\mathrm{O}$ mesmo se passa na legislação que, frequentemente, utiliza acriticamente as expressões mencionadas, sem distinguir ou selecionar com rigor uma dada designação constante para uma determinada espécie de ato.

De qualquer maneira, as instituições privadas de ensino autorizadas fazem a prestação de um bem público coexistente com o serviço público prestado pelo Estado como seu dever.

Retornando ao capítulo da educação, o artigo 209 pode ser cotejado com o artigo 213 da Constituição cujo teor diz:

Os recursos públicos serão destinados às escolas públicas, podendo ser dirigidos às escolas comunitárias, confessionais ou filantrópicas, definidas em lei, que: I - comprovem finalidade não lucrativa e apliquem seus excedentes financeiros em educação; 


\section{movimento}

faculdade de educação - programa de pós-graduação em educação

universidade federal fluminense issn 2359-3296

ano 3 número 5 - 2016

II - assegurem destinação de seu patrimônio a outra escola comunitária, filantrópica ou confessional. ou ao poder público, no caso de encerramento de suas atividades.

$\S 10$. Os recursos de que trata este artigo poderão ser destinados a bolsas de estudo para o ensino fundamental e médio, na forma da lei, para os que demonstrarem insuficiência de recursos, quando houver falta de vagas e cursos regulares da rede pública na localidade da residência do educando, ficando o poder público obrigado a investir prioritariamente na expansão de sua rede na localidade.

$\S 20$. A atividades universitárias de pesquisa e extensão poderão receber apoio financeiro do poder público. (Brasil, 1988)

Assim, a Constituição redefine a situação: aquele ensino privado geral (art. 209), não é impedido de buscar o lucro (por oposição à letra do art. 213, I). Nesse caso, ele é, no seu teor, tipicamente capitalista. O lucro, como inerente ao sistema contratual de mercado, é aceito e reconhecido por um segmento destas escolas privadas e elas podem ser autorizadas como integrantes dos sistemas de ensino. $E$ isto é novo.

Distinguindo-se deste modo de ser escola, outras modalidades indicadas (art. 213) formalmente possuem uma presença não tipicamente capitalista dentro de uma economia de mercado.

Estas modalidades se subdividem em escolas filantrópicas, comunitárias e confessionais e por não terem finalidade lucrativa fazem o exercício institucional de ensinar dentro de uma visão não-possessiva e, desse modo, podem receber recursos públicos como bolsas ou programas de apoio às atividades de pesquisa (art. 213, §§ 10 e 2o), quanto se isentarem de impostos (art.150, VI, c). ${ }^{2}$ Tais escolas não possuem finalidade lucrativa. Mas isso não quer dizer que, no

${ }^{2}$ Esta franquia já fazia parte das Constituições de 1934 (art. 17, X e art. 154) e de 1946 (art. 30, $V, b)$. 


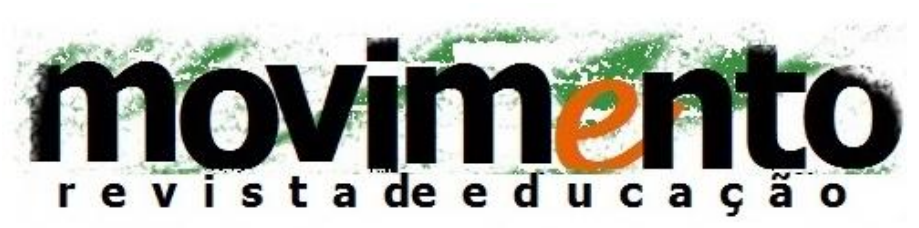

faculdade de educação - programa de pós-graduação em educação

universidade federal fluminense issn 2359-3296

ano 3 número 5 - 2016

interior do sistema contratual de mercado, não possam auferir algum lucro. Como visto acima (art. 213) o que está em jogo é a finalidade deste lucro.

A escola filantrópica é aquela altruísta no sentido de buscar compensar os mais evidentes entraves ao trânsito de determinados indivíduos carentes ao estatuto pleno da cidadania.

A escola comunitária busca estes ou outros caminhos (p. ex., o da manutenção de formas cooperativas), mas sempre dentro de uma vertente que combina pequenos pagamentos, voluntariado e serviços, por exemplo, dentro de grupos, bairros ou regiões vulneráveis ou então uma finalidade voltada para educação inclusiva.

A escola confessional será objeto da autorização, menos pela inexistência de herdeiros ou pelo voto de pobreza e mais pela indicação de prática não-lucrativa inerente à solidariedade, em princípio oposto ao "individualismo possessivo". Ela também é assim designada porque, em sua identidade religiosa, busca transmitir uma diferença constituída pelos princípios de uma religião que se apresenta por meio de valores e símbolos próprios daquela denominação.

Em síntese, por patrocinarem um bem público, elas herdam a tradição de uma escola privada que, por comprovar finalidade não-lucrativa, obtém tanto o reconhecimento oficial (como qualquer outra escola privada), quanto a possibilidade de recursos públicos, na forma do art. 213 da Constituição Federal.

Finalmente, a escola privada típica, desde que se dedique à pesquisa e à extensão, pode receber apoio financeiro do poder público para estas funções. 


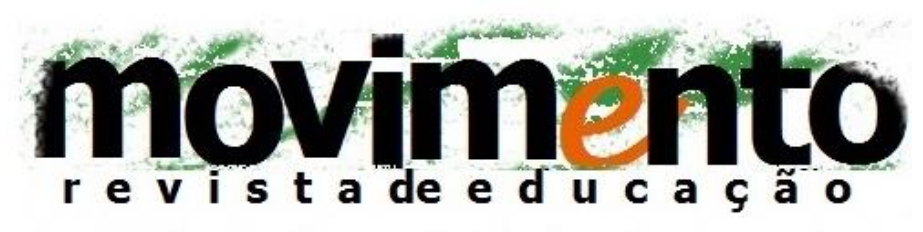

faculdade de educação - programa de pós-graduação em educação

universidade federal fluminense

issn 2359-3296

ano 3 número 5 - 2016 


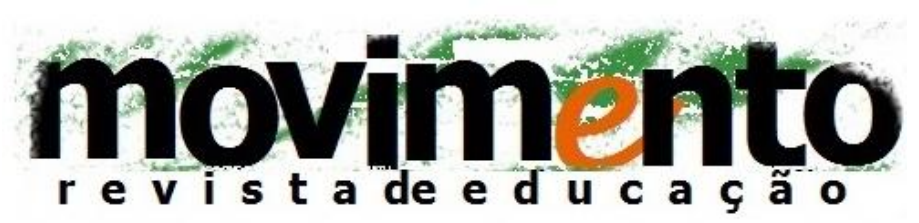

faculdade de educação - programa de pós-graduação em educação

universidade federal fluminense issn 2359-3296

ano 3 número 5 - 2016

\section{A Lei de Diretrizes e Bases da Educação Nacional e a Rede privada}

As Diretrizes e Bases da Educação Nacional, lei n. 9.394/96, confirmam os dispositivos da Constituição Federal. Mas, sem ferir tais dispositivos, ela os explicita como é próprio de uma lei ordinária. Assim, no que concerne à escola privada, ela obedece e participa dos princípios e fins da educação nacional, ressalvados os casos em que um ou outro princípio se restrinja ao ensino público. Tal é o caso do art. 3o, incisos VI e VIII relativos à gratuidade e à gestão democrática.

A LDB, contudo, adicionou, no seu art. 7o, que é relativo ao ensino privado, o cumprimento também das normas do respectivo sistema de ensino (inciso I) e a capacidade de autofinanciamento, ressalvado o previsto no art. 213 da Constituição Federal (inciso III).

Em termos de pertencimento ao respectivo sistema de ensino, assinale-se o inciso II do art.16; o inciso III do art. 17 e seu parágrafo único e o inciso II do art. 18.

Quando à sua definição, vale a pena reproduzir os artigos 19 e 20 diretamente referidos às categorias de público e de privado.

Art. 19. As instituições de ensino dos diferentes níveis classificam-se nas seguintes categorias administrativas:

I - públicas, assim entendidas as criadas ou incorporadas, mantidas e administradas pelo Poder Público;

II - privadas, assim entendidas as mantidas e administradas por pessoas físicas ou jurídicas de direito privado. 


\section{$\operatorname{movim}_{\text {revistade educaço }}$}

faculdade de educação - programa de pós-graduação em educação

universidade federal fluminense issn 2359-3296

ano 3 número 5 - 2016

Art. 20. As instituições privadas de ensino se enquadrarão nas seguintes categorias;

I - particulares, em sentido estrito, assim entendidas as que são instituídas e mantidas por uma ou mais pessoas físicas ou jurídicas do direito privado que não apresentem as características dos incisos abaixo:

II - comunitárias, assim entendidas as que são instituídas por grupos de pessoas físicas ou por uma ou mais pessoas jurídicas, inclusive cooperativas educacionais, sem fins lucrativos, que incluam na sua entidade mantenedora representantes da comunidade.

III - confessionais, assim entendidas as que são instituídas por grupos de pessoas físicas ou por uma ou mais pessoas jurídicas que atendem a orientação confessional e ideologia específicas e ao disposto no inciso anterior;

IV - filantrópicas, na forma da lei. (Brasil, 1988)

O Código Tributário Nacional (CTN) de 2001, em seu art. 14, estabeleceu as condições pelas quais estas instituições privadas sem fins lucrativos podem gozar as imunidades previstas no art. 150 da Constituição.

I - não distribuírem qualquer parcela de seu patrimônio ou de suas rendas, a qualquer título;

II - aplicarem integralmente, no País, os seus recursos na manutenção dos seus objetivos institucionais;

III - manterem escrituração de suas receitas e despesas em livros revestidos de formalidades capazes de assegurar sua exatidão. (Brasil)

Por seu lado, o Decreto № 3048 de 1999 ao regulamentar a isenção de contribuições, dispõe no seu art. 206:

Fica isenta das contribuições a entidade que [...] IV - promova, gratuitamente, a assistência social beneficente a pessoas carentes, em especial a crianças, adolescentes, idosos e portadores de deficiência; $\S 2^{\circ}$ Considera-se pessoa carente a que comprove não possuir meios de prover a própria manutenção, nem tê-la provida por sua família. (Brasil, 2016c) 


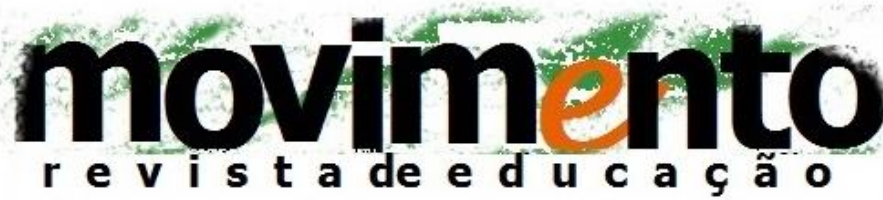

faculdade de educação - programa de pós-graduação em educação

universidade federal fluminense issn 2359-3296

ano 3 número 5 - 2016

Com relação às entidades de filantropia, o Decreto № 2.536 de 1998, em seu art. $3^{\circ}$, explicita as condições pelas quais uma entidade possa fazer jus do Certificado de Entidade de Fins Filantrópicos, as quais devem ser comprovadas durante 3 anos antes da solicitação:

I - estar legalmente constituída no País e em efetivo funcionamento;

II - estar previamente inscrita no Conselho Municipal de Assistência Social do município de sua sede, se houver, ou no Conselho Estadual de Assistência Social; III - estar previamente registrada no Conselho Nacional de Assistência Social CNAS;

IV - aplicar suas rendas, seus recursos e eventual resultado operacional integralmente no território nacional e na manutenção dos seus objetivos institucionais;

$V$ - aplicar as subvenções e doações recebidas nas finalidades a que estejam vinculadas;

$\mathrm{VI}$ - aplicar anualmente, em gratuidade, pelo menos vinte por cento da receita bruta proveniente da venda de serviços, acrescida da receita decorrente de aplicações financeiras, locação de bens, de venda de bens não integrantes do ativo imobilizado e de doaçõ̃es particulares, cujo montante nunca será inferior à isenção das contribuições sociais usufruídas;

VII - não distribuir resultados, dividendos, bonificações, participações ou parcela do seu patrimônio, sob nenhuma forma ou pretexto;

VIII - não perceberem seus diretores, conselheiros, sócios, instituidores, benfeitores ou equivalentes, remuneração, vantagens ou benefícios, direta ou indiretamente, por qualquer forma ou título, em razão das competências, funções ou atividades que lhes sejam atribuídas pelos respectivos atos constitutivos; IX - destinar, em seus atos constitutivos, em caso de dissolução ou extinção, o eventual patrimônio remanescente a entidades congêneres registradas no CNAS ou a entidade pública; $X$ - não constituir patrimônio de indivíduo ou de sociedade sem caráter beneficente de assistência social. (Brasil, 2016c)

Muitas instituições religiosas e comunitárias buscam também este certificado devido à isenção da quota patronal de Previdência Social tornando-se também filantrópicas. Assim as contribuições da Previdência Social a que estariam 


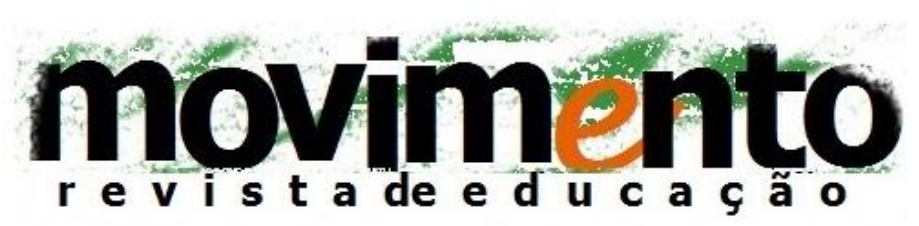

faculdade de educação - programa de pós-graduação em educação

universidade federal fluminense issn 2359-3296

ano 3 número 5 - 2016

submetidas se fossem só entidades confessionais, são substituídas por gratuidades dentro de um determinado porcentual (20\% da renda bruta), segundo o Decreto n. 2.536 de 1998.

Certamente a temática geral aqui tratada contém outras dimensões em nossa história da educação. Uma delas se refere ao papel da família na oferta da educação, mesmo na oferta da educação escolar no lar e na questão da obrigatoriedade.

A lei n. 11.096, de 13/01/2005, institui o Programa Universidade para Todos PROUNI, regula a atuação de entidades beneficentes de assistência social no ensino superior

Art. 1o Fica instituído, sob a gestão do Ministério da Educação, o Programa Universidade para Todos - PROUNI, destinado à concessão de bolsas de estudo integrais e bolsas de estudo parciais de $50 \%$ (cinquenta por cento) ou de $25 \%$ (vinte e cinco por cento) para estudantes de cursos de graduação e sequenciais de formação específica, em instituições privadas de ensino superior, com ou sem fins lucrativos. (Brasil, 2016c)

Importante destacar que na Exposição de Motivos da Medida Provisória n. 213 de 2004, o do Programa Universidade para Todos (PROUNI), posteriormente convertida na lei acima referida, há aspectos significativos a serem destacados, em especial no confronto com o $\S 20$ do art. 213 da Constituição do qual não constam as atividades de ensino das instituições com fins lucrativos como recebedoras de apoio financeiro da parte dos poderes públicos. 


\section{$\operatorname{movim}_{\text {revistade educąis }}$}

faculdade de educação - programa de pós-graduação em educação

universidade federal fluminense issn 2359-3296

ano 3 número 5 - 2016

Entretanto, a Medida Provisória encontrou na categoria de entidade beneficente de assistência social uma espécie de respaldo para o estudante que tenha cursado o ensino médio completo em escola da rede pública ou em instituições privadas na condição de bolsista integral; a estudante portador de necessidades especiais, nos termos da lei; a professor da rede pública de ensino para os cursos de licenciatura e de pedagogia, destinados à formação do magistério da educação básica. ${ }^{3}$

A Exposição explicita o desiderato do governo na democratização do ensino superior ao estudante de baixa renda. Com este conjunto de justificativas, o art. $8^{\circ}$ da lei $n$. 11.086/2005 isenta as mantenedoras de uma série de impostos enquanto durar o termo de adesão. Vale a pena, ademais, citar mais alguns considerandos próprios desta Exposição em que o ensino superior comparece como categoria de bem essencial:

10. Nota-se, com isso, que o presente projeto de Medida Provisória visa dar à educação superior um status diferenciado, intenta elevá-la à categoria de bem essencial e que, destarte, não poderia se submeter ao regime tributário e fiscal indistintamente aplicável à atividade empresarial orientada pela mercadoria e pelo consumo. Ora, ninguém ignora que os tributos cobrados de instituições de ensino superior são repassados aos estudantes por meio da cobrança de mensalidades, conforme a racionalidade econômica empresarial.

11. Por essa razão, a política de acesso democrático ao ensino superior - para estudantes de baixa renda e também para minorias étnico-raciais, como prevê o presente Artigo $7^{\circ}$, inciso II, deste projeto de Medida Provisória - vem associada a medidas tributárias. O tratamento fiscal diferenciado conferido às atividades relativas ao ensino superior não visa simplesmente a desonerar as mantenedoras de instituições de ensino superior, mas sim e precisamente reduzir o custo da mensalidade de cursos de graduação e sequenciais de formação específica, ou seja, tem como meta desonerar o bolso do estudante, em especial, do estudante

\footnotetext{
3 Para um conhecimento maior de entidade beneficente há que se recorrer às leis n. 8.742/1993; lei n. 12.101/2009 e lei n. 12.868/2013.
} 


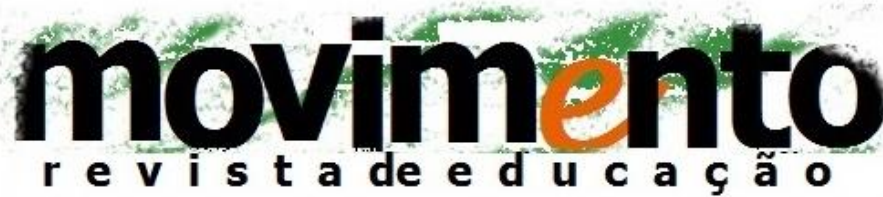

faculdade de educação - programa de pós-graduação em educação

universidade federal fluminense issn 2359-3296

ano 3 número 5 - 2016

de baixa renda que, de outra forma, ficaria privado de formação educacional superior. ${ }^{4}$

12. Acrescente-se que as entidades beneficentes de assistência social são reguladas nos termos do Artigo 10 e respectivos parágrafos, no presente projeto de Medida Provisória. A condição de filantrópica está atrelada ao oferecimento de bolsas de estudo integrais à proporção de 10\% (dez por cento) dos estudantes regularmente matriculados e à destinação de pelo menos $20 \%$ (vinte por cento) da receita em gratuidade. (Brasil, 2016c)

Ao que parece, com estes últimos dispositivos, a matização entre escola com ou sem finalidade lucrativa tende a esmaecer, restando ao poder público a cobrança das condicionalidades postas.

\section{Conclusão}

Pode-se verificar que a Constituição Federal de 1988 herda a tradição da concessão da função pública aos serviços da educação, só que agora a concessão se converteu em autorização.

Do ponto de vista jurídico-constitucional, observa-se que desde o Império, a educação escolar regular é uma função pública que o Estado avoca a si ou a imputa a quem deseja assumi-la sob condições. Após a República, esta formulação vai se evidenciando de modo cada vez mais claro, seja através da Constituição ou das diferentes leis de diretrizes e bases, excetuado, em nível federal, o tempo existente sob a Reforma Rivadávia.

\footnotetext{
${ }^{4} \mathrm{O}$ inciso II do art. $7^{\circ}$ se refere a uma condicionalidade para a adesão ao PROUNI: percentual de bolsas de estudo destinado à implementação de políticas afirmativas de acesso ao ensino superior de autodeclarados negros e indígenas. Este dispositivo permanece na Lei $\mathrm{n}$. $11.096 / 2005$.
} 


\section{movimento \\ faculdade de educação - programa de pós-graduação em educação \\ universidade federal fluminense issn 2359-3296 \\ ano 3 número 5 - 2016}

A nova Constituição, como vimos, inova ao aceitar o ensino autorizado regido, concorrentemente, pelas leis de mercado e pelas da educação sub lege. A novidade nela presente consiste na aceitação da lucratividade no interior dos sistemas de educação. Já para as escolas comunitárias, confessionais e filantrópicas, também autorizadas, fazem parte do sistema contratual de mercado sob regras específicas quanto à lucratividade, em especial usufruindo de isenção de impostos.

Neste sentido, ambas as escolas são privadas e podem ser reconhecidas e devem se submeter às normas constitucionais, às leis educacionais, trabalhistas e outras de domínio conexo. Mas o que as diferencia é a aceitação plena ou reduzida do ímpeto possessivo de mercado e a destinação da lucratividade.

É no grau de redução desta possessividade que reside a possibilidade de subvenção pública e isenção de impostos. Embora as escolas com finalidade lucrativa não possam usufruir de isenções postas no art. 150 da Constituição, convertidas em entidades beneficentes, nos termos da lei do PROUNI, elas também passaram, via mantenedoras, a gozar de determinadas isenções.

A Lei de Diretrizes e Bases explicitou mais alguns elementos relativos à organização administrativa e pedagógica da educação nacional. Contudo, ao se recorrer a outros documentos legais para a caracterização de escola com ou sem fim lucrativo, em especial os que dispõem sobre entidades beneficentes, podese perguntar se é cabível tal categorização para as entidades com finalidade lucrativa. 


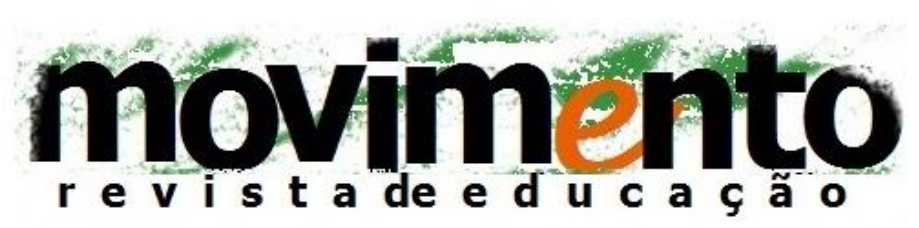

faculdade de educação - programa de pós-graduação em educação

universidade federal fluminense issn 2359-3296

ano 3 número 5 - 2016

Todavia, a educação como dever de Estado o obriga a assumi-la como seu dever maior e, face à consciência da sociedade civil, atendê-la como um direito ampliando a face pública do próprio Estado.

Boa parte deste dever está, agora, consignado no Plano Nacional de Educação, lei n. 13.005/2014, o qual, por meio de vinte metas e respectivas estratégias, se propõe a resgatar o caráter democrático e qualitativo da educação. E o Plano não se omite em referendar a busca do atingimento de certas estratégias por meio da chamada à escola privada à luz da colaboração. Ao mesmo tempo, o Plano também quer promover a regulação da oferta da educação básica pela iniciativa privada, de forma a garantir a qualidade e o cumprimento da função social da educação, segundo a meta 7, estratégia 35. E impõe, outrossim, por meio do princípio da avaliação de qualidade exigências que devem ser cumpridas por qualquer instituição que ofereça educação escolar.

\section{Referências Bibliográficas}

BANDEIRA DE MELLO, Celso Antônio. Curso de Direito Administrativo. São Paulo: Malheiros, 2006.

BARBOSA, Rui. Reforma do ensino primário. In: de Janeiro: Ministério da Educação e Saúde, 1947. v.10, t.4.

Obras completas. Rio

BRASIL. Constituição. 1988. Constituição da República Federativa do Brasil. Brasília: MEC, 1988. Disponível em: http://www.planalto.gov.br/ccivil _03/constituicao/constituicao.htm. Acesso em: 3 nov. 2016.

BRASIL. Coleção das Leis do Império (1808-1889). Disponível em: http//:www2.camara.legbr/atividade-legislativa/legislação. Acesso em: 3 nov. 2016a. 


\section{movimento \\ faculdade de educação - programa de pós-graduação em educação \\ universidade federal fluminense issn 2359-3296 \\ ano 3 número 5 - 2016}

BRASIL. Coleção das Leis da República (1889-2000). Disponível em: http//:www2.camara.legbr/atividade-legislativa/legislação. Acesso em: 3 nov. $2016 \mathrm{~b}$.

BRASIL. Palácio do Planalto, Presidência da República. Conheça o material legislativo produzido no Brasil. Disponível em: http://www2.planalto.gov. br/acervo/legislação. Acesso em: 3 nov. 2016c.

DI PIETRO, Maria Sylvia Zanella. Direito Administrativo. São Paulo: Atlas, 2004.

MARTINS FILHO, Yves Gandra da Silva. O Ordenamento Jurídico Brasileiro. Revista Jurídica Virtual Brasília, v.1, n.3, jul. 1999. 9p. Disponível em: https://revistajuridica.presidencia.gov.br/index.php/saj/article/view/1054/1038. Acesso em: 17 nov. 2016.

MEIRELLES, Hely Lopes. Direito Administrativo Brasileiro. São Paulo: Malheiros, 1993

NAUFEL, José. Novo dicionário jurídico brasileiro. São Paulo: Icone, 1988. 